Paulo Brito do Prado

Universidade Federal Fluminense, Niterói, RJ, Brasil

Eliane Martins de Freitas

Universidade Federal de Goiás, Catalão, GO, Brasil

\title{
Uma poética da emancipação feminina nos sertões goianos (século XIX)
}

Resumo: O presente texto visa compreender como os espaços de instrução e leitura, existentes na antiga capital goiana (Goiás), na segunda metade do século XIX e início do século XX, foram (re)apropriados por algumas mulheres de forma a lhes garantir a expressão de suas experiências. Para tanto, partindo da documentação do Gabinete Litterario Goyano, criado em 1864, buscamos, por meio do protagonismo de Silvina Ermelinda Xavier de Britto e Jacintha Luiza do Couto Brandão Peixoto, compreender questões em torno da instrução das mulheres, de seu exercício da leitura, de um ensaio de emancipação, representado pelos pedidos de voto das goianas em 1889 e das táticas manejadas por estas mulheres na expectativa de exercitar sua intelectualidade, ainda que Ihes fosse apresentado como um caminho cheio de obstruçóes. Palovras-chave: Emancipação feminina; Intelectuais; Gabinete Litterario Goyano; Instrução.

Ler a realidade às avessas, partindo de sua opacidade, para não permanecer prisioneiro dos esquemas da inteligência [...] Carlo Ginzburg (2004, p. 14).

Desde a publicação, em 1984, do hoje clássico Quotidiano e Poder em São Paulo no Século XIX, da historiadora Maria Odila Leite da Silva Dias, que concebemos ser a pesquisa no campo da história das mulheres no Brasil, assim como em outros países, uma operação baseada em silêncios, exclusões e espaços em branco. Visto que, conforme a autora, "a memória social da vida das mulheres vai-se perdendo mais por esquecimento ideológico do que por uma real inexistência de documentos" (DIAS, 1984, p. 7).

Pensar neste "esquecimento ideológico" e em suas intenções muito relacionadas à dominação masculina, e que atravessam a própria narrativa da história, nos atinou para 
que realizássemos a leitura de nossa realidade - presente e passada - às avessas, partindo das zonas mudas e das opacidades para não nos aprisionarmos em esquemas de inteligência, ou contribuir para a conversão das mulheres em "silêncios da história". Assinalamos, pari passu a Maria Odila, que buscar traços da atuação feminina particularmente em domínios reservados aos homens não é tarefa fácil, dado que muitas vezes os indícios do protagonismo feminino permanecem ocultos na informalidade de suas trajetórias e por esta razão se prendem em silêncios.

É constatando este caráter "silencioso" da história das mulheres que nos aproximamos da metonímia de Michelle Perrot (2005). O uso que a historiadora faz da categoria "silêncio" para problematizar um elemento tomado como de menor expressão na narrativa histórica é, sem dúvida, uma ferramenta analítica útil para manipularmos a categoria gênero e compreendermos a constituição do social.

As mulheres são silêncios na e da história e estes silêncios têm dimensões distintas. Eles têm formas e sentidos vários, que precisam ser explorados. Daí servirem como possibilidade para trabalharmos "suas contradições constitutivas" e os "deslocamentos de palavras em presenças e ausências" (Eni ORLANDI, 2007, p. 24 - 25). O manuseio dos silêncios e a consideração de seus múltiplos sentidos nos permitem questionar uma história escrita sobre matrizes que insistem em valorizar como objeto único "um sujeito humano neutro ou universal [e masculino]" (Joan SCOTT, 2008, p. 99).

Dessa maneira, foi pensando nas metáforas escriturárias, nas políticas da história e nas relações entre os sexos que nos chamou atenção notícias sobre o caráter, usos e costumes do povo goiano, veiculadas por Raymundo José da Cunha Mattos em sua Chorographia Histórica da Província de Goyaz, escrita em 1824. Em suas memórias o cronista destacou, dentre variados aspectos da gente goiana, ser as mulheres "honestas, afáveis e muito mais polidas do que se deveria esperar de terras tão distantes das cidades da beira mar, assento da civilização" (MATTOS, 1978, p. 92). Nada mais afastado da representação construída pelo viajante Augusto Saint-Hilaire (1975), em sua Viagem à Província de Goyaz, realizada em 1819. Nas palavras do naturalista, quando de sua passagem por Vila Boa (atual Cidade de Goiás), os traços da mulher goiana não tinham "nenhuma delicadeza, seus gestos são desgraciosos e sua voz não tem doçura. Como não recebem educação, sua conversa é inteiramente desprovida de encanto. São inibidas e estúpidas, e se acham reduzidas praticamente ao papel de fêmeas para os homens" (1975, p.54).

Se as notícias veiculadas por Raymundo José da Cunha Mattos, na primeira metade do século XIX, não coadunam com a narrativa do viajante francês, é correto falar que as notícias da segunda metade do século XIX estão ainda mais distantes. Já em 1868, Honorata Minelvina Carneiro de Mendonça' ${ }^{1}$, goiana, mas moradora da Corte desde a década de 1870 (VASCONCELOS, 2010), publicou, dentre tantas outras poesias, Saudades de minha terra. Parodia por uma goiana a sua irmã na Côrte (MENDONÇA, 1868, p. 39-40). Além de contribuir com o Jornal das Famílias e O Domingo, Honorata Minelvina tornou-se a primeira goiana a publicar um livro de que se tem conhecimento. $A$ Redenção, reunião de poesias religiosas, teve alguma circulação na Corte em 1875, ano de sua publicação. Ao lado dessa notícia, há várias outras, de concertos musicais, nos quais as mulheres da elite local tinham participação intensa. Nestes eventos, elas recitavam poesias ou cantavam músicas clássicas, demonstrando certo refinamento e instrução. Exemplo disso é a notícia veiculada pelo jornal Correio Official sobre as comemorações locais do Dia da Província e que

\footnotetext{
1 A naturalidade de Honorata Minelvina Carneiro de Mendonça foi atribuída ao estado do Piauí em estudo produzido por Sacramento Blake em 1893, todavia, após pesquisas realizadas por Gilberto Mendonça Teles, este constatou que se tratava de uma goiana que mudara para a Corte (VASCONCELOS, 2010).
}

2 Revista Estudos Feministas, Florianópolis, 26(2): e 
informavam "um esplendido sarau, na casa escolhida, para onde concorreram muitas Senhoras e grande numero de cavaleiros, ostentando aquellas toilettes de puro gosto, próprio de corte" (CORREIO OFFICIAL, 1874, p. 03). Em 17 de novembro de 1880, numa quarta-feira, realizou-se em uma das salas do Palácio da Presidência, um segundo sarau e concerto musical, que contou com a participação de várias senhoras e senhoritas que, em 1871, figuravam entre as mulheres primeiras sócias do Gabinete Litterario Goyano, dentre elas: "Josefina de Bulhões, Anna e Leonor Xavier de Barros, Maria Nazareth Xavier Barros, Josefina Fleury, Anna Gabriella e Maria Xavier de Almeida, Angela de Bulhões" (CORREIO OFFICIAL, 1880, p. 04).

E, por fim, corroborando este conjunto de pistas, a historiografia sobre a educação em Goiás nos mostra que, ao longo da constituição política do estado - fortemente apoiada em alicerces oligárquicos - a preocupação com a instrução para as mulheres esteve presente em várias iniciativas.

Temos clareza de que a maioria das instituições se limitou a atender os segmentos sociais abastados, mas acreditamos que estes estabelecimentos não podem ser negligenciados. Faz-se necessário tomá-los como potenciais espaços de circulação de ideias, cujas mediações, inclusive, explicam, em parte, a invenção de tradições literárias em Goiás, particularmente aquelas representadas na instalação das escolas de Pacifica Josefina de Castro, Mestra Inhola, da Escola Pública Feminina de Silvina Ermelinda Xavier de Britto e do Gabinete Litterario Goyano, em 1864. Cabe-nos, assim, perguntar: É possível pensar estas instituições como potenciais lugares para o exercício de jogos de gênero ou relacionamentos que oportunizaram às mulheres exercer influências junto às portas do poder e galgar uma emancipação? Se olharmos para estas instituições com uma lente feminizada, encontraremos nelas a constituição de lugares que regularam a ponte, permitindo a algumas mulheres transitar da esfera privada para a esfera pública? Acreditamos que o exercício intelectual e remunerado de algumas goianas, as escolas e o Gabinete Litterario foram espaços de fuga para as mulheres. As escolas e o Gabinete eram lugares onde elas podiam ler e pensar sem que fossem duramente interrompidas pelos afazeres domésticos ou pela figura masculina. Por menor que fosse sua expressão no interior destas instituições é importante considerar ser, ali, local de interiorização/exteriorização de experiências, de algum prazer e de poderes.

Neste sentido, buscamos, no presente texto, refletir sobre a intermediação dos jogos de gênero (Luc CAPDEVILA, 2001) em escolas femininas (e mistas), na participação das mulheres no Gabinete e num ensaio de emancipação, representado pelos pedidos de voto das goianas em 1889. Nosso objetivo é compreender, a partir da atuação de Silvina Ermelinda Xavier de Britto e Jacintha Luiza do Couto Brandão Peixoto, como os espaços de instrução e leitura, mesmo que dirigidos por homens, foram (re)apropriados pelas mulheres de forma a lhes garantir a interiorização/expressão de experiências e, consequentemente, o exercício do poder.

Os indícios e pistas assinalando suas resistências e a vontade de emancipação permeou o trabalho com muitas perguntas. Estas questões relacionam-se a diferentes aspectos das trajetórias de Jacintha Luiza ${ }^{2}$, comerciante, e Silvina Ermelinda, professora de primeiras letras da escola feminina de Goiás. Interessa-nos entender de que forma tantas obras literárias chegaram até às suas mãos, uma vez que o acesso a livros era tido como algo difícil na região? A posse de volumes bibliográficos e da literatura mundial, particularmente a francesa, poderia ser compreendida como um desejo de emancipar-se?

${ }^{2}$ Jacintha Luiza do Couto Brandão Peixoto é mãe da poetisa Cora Coralina, pseudônimo de Ana Lins do Guimarães Peixoto Bretas (1889-1985). 
O que diferencia estas mulheres de tantas outras que participavam do Gabinete Litterario Goyano, a partir de 1871, mas que não tiveram o mesmo protagonismo e visibilidade pública? Em função destas e de muitas outras indagações optamos olhar para o Gabinete com uma atenção mais refinada, pois, de certa forma, foi em seu interior que as mulheres projetaram mecanismos para expressar ideias em meio ao mundo masculino e tornar públicas suas experiências.

Por fim, cabe dizer que o texto está dividido em dois momentos: no primeiro, trazemos alguns elementos sobre a questão da instrução em Goiás, bem como, sobre o Gabinete; e no segundo, voltamos nosso olhar para a atuação de Jacintha e Silvina. As fontes utilizadas compõem o acervo documental do Gabinete, dentre elas: Atas, Estatutos, Relatórios dos Presidentes da Província de Goiás, e jornais diversos, que compreendem o período de 1864 a 1936.

\section{Nem Goiás era uma ilha: Gabinete Litterário, gênero e mediações literárias}

Parte importante da historiografia sobre Goiás contribuiu para reforçar uma ideia de isolamento, colocando a região numa posição em separado do resto do Brasil e supervalorizando as dificuldades de acesso para se alcançar estas paragens, durante os séculos XIX e meados do XX. Alguns apontamentos de Luiz Palacin (1976) e Francisco Itami Campos (1987) deixam a impressão de que Goiás, em alguns momentos, estivesse ilhado do resto do Brasil.

As afirmações relativas à ausência de vias de rodagem ou de manobras das oligarquias locais em manter Goiás isolada das outras regiões não se sustentam. Na verdade, elas são contrariadas no instante em que se nota a quantidade considerável de viajantes estrangeiros percorrendo Goiás durante o referido recorte de tempo, registros de diferentes informações alcançando estes sertões, circulação de pessoas entre Goiás, Rio de Janeiro, São Paulo e Minas Gerais, relatos de Augusta de Faro Fleury Curado (1896), publicados por sua filha, Maria Paula Fleury de Godoy (1961) acerca da viagem de mudança do Rio de Janeiro para Goiás, compra de livros efetivada pelo Gabinete Litterario a partir de 1871 e registros cotidianos de Anna Joaquina da Silva Marques em seu diário de lembranças (MARQUES, 1881-1930). Tantos registros deixam evidências de que Goiás não estava isolado das outras regiões brasileiras.

Ainda que ocupasse uma posição periférica no cenário econômico do Império e posteriormente, da República, e que seu cotidiano tenha sido marcado pelas dificuldades em acessar a região, é importante frisar que dificilmente Goiás permaneceu ilhada. Na segunda metade do século XIX, "naturalistas, etnógrafos e historiadores elegeram a natureza e a sociedade do país como objetos de estudos dos quais resultam importantes obras descritivas e analíticas" (Andréa LEÃO; Edson FARIAS, 2016, p. 631). As memórias desses viajantes, as notícias de jornais e os registros do Gabinete Litterario deixam ver que, mesmo com certo atraso, as novidades, ideias, modas e notícias alcançam estes sertões. Consideramos que com o "incremento do comércio de livros, as publicações, em fascículos, das viagens e o advento da leitura massiva dos jornais de vulgarização científica" (LEÃO; FARIAS, 2016, p. 632), os assuntos que concerniam ao cotidiano da gente goiana universalizaram-se "numa cultura política ampliada" (p. 632).

Desde a primeira metade do século XIX já se observava um incipiente debate em torno da instrução, da leitura e do cultivo da intelectualidade nos sertões de Goiás. Tal debate insere-se no contexto da necessidade funcional de ler e escrever para atender demandas da vida cotidiana, estimulando diversos locais do Brasil à instalação de 
bibliotecas e gabinetes de leitura. De acordo com Valdeniza Barra (2008, p.86), entre "o século XIX e XX, o acesso à leitura representara o acesso à cultura, portanto às obras que devem permear a mente e a ética". É possível verificar, corroborando com esta visão da importância do acesso à leitura, que a escassez de livros era uma preocupação constante nos relatórios presidenciais da província de Goiás (Genesco BRETAS, 1991, p. 86). Daí o estímulo para se instalar escolas e o Gabinete Litterario Goyano.

Por mais que o temário da instrução tenha se restringido, muitas vezes, ao campo dos discursos, é preciso observar cuidadosamente o contexto intelectual em que foram cultivados o Lyceu de Goyaz, a escola normal, as femininas e o Gabinete Litterario Goyano. Entre 1830 e 1864, Goiás recebeu bibliotecas públicas, escolas e o Gabinete. A biblioteca pública de Pirenópolis, por exemplo, foi instalada em 1830. O Lyceu de Goyaz foi instalado em 1846, a escola normal entre 1858 e 1882 e o Gabinete em 1864 (Maria CANEZIN; Walderês LOUREIRO, 1994).

Goiás recebeu, na segunda metade do século XIX, várias escolas. Nos jornais é possível ver a movimentação de meninas nestas escolas, todavia nos pareceu que seu público limitava-se aos segmentos sociais mais abastados. Só observaremos maior atenção à instrução de meninas pobres após a instalação do Colégio Sant'Anna (1889) e que teve sala específica para atender este público. Referências a isto podem ser encontradas no Lidador (1909 - 1916), periódico oficial da Diocese goiana.

No que tange à escola normal, é a partir dos anos de 1870 que a preocupação com a pouca frequência nas escolas primárias e no $L y c e u$, bem como com a evasão dos alunos, que se fortalece a ideia de abrir "as portas da instrução à mulher goiana e que se [fizesse] dela a mestra" (Maria Augusta de Sant'Anna MORAES, 1972, p. 33). Entretanto, a partir da segunda metade do século XIX, os jornais da época dão notícias de escolas femininas em diferentes cidades e vilas de Goiás, bem como da atuação de várias professoras de primeiras letras, dentre elas: Pacífica Josefina de Castro (Mestra Inhola), Luiza Joaquina (Mestra Lili), Silvina Ermelinda Xavier de Brito (Mestra Silvina), D. Maria Romana da Purificação, D. Angélica de Souza Lobo, D. Maria Victoria de Moraes Brandão e Mestra Maria Cyriaca Ferreira.

Durante o governo de Aristides de Souza (1879 - 1880) houve incentivos para que as mulheres entrassem de vez no ambiente da instrução. Em relatório apresentado à Assembleia Legis/ativa Provincial de Goyaz, em 01 de junho de 1879, o presidente da província destacou que já "desaparece do systema de ferula e de terror, o apostolado do magistério; apostolado de brandura, de paciência, de dedicação, de amor, quadra mais á mulher do que ao homem" (SPINOLA, 1879, p. 01). É evidente ter Spínola recorrido às imagens de "doçura" e "maternidade", características da "mulher simbólica" (Stéphane MICHAUD, 1991, p. 147) do século XIX. Todavia, o fato de incentivar a instrução e o trabalho de mulheres evidencia sua tímida entrada em espaços anteriormente dominados pelo elemento masculino.

Ainda que a feminização dos espaços significasse perca de capital simbólico e financeiro, já fica a imagem de que as mulheres, em momento algum, aceitaram a total submissão imposta pela dominação masculina. Embora a autorização para que tomassem lugares nos espaços da ciência estivesse fortemente relacionado ao processo de liberalização tutelada, não ignoramos terem as mulheres, manejado táticas e golpes para subverter os projetos da "dominação simbólica" (Roger CHARTIER, 1995; Rachel SOIHET, 1989).

É neste contexto de intensificação da preocupação com a educação, do discurso da pouca circulação de livros e da necessidade de difusão de ideias modernas nos sertões goianos que um grupo de "homens de bem" da antiga capital goiana propôs a criação, em 1864, do Gabinete Litterario Goyano, a partir da constituição de uma 
Associação. Segundo Bretas (1991, p. 409), Raymundo Sardinha da Costa, idealizador da proposta, "imaginou uma sociedade, composta dos homens mais representativos da Capital, homens que liam ou poderiam ler com proveito bons autores" (grifos nossos).

Raymundo Sardinha destacou homens que detinham capital financeiro e, consequentemente, capital cultural suficiente para garantir a circulação de ideias em Goiás e sustentar o Gabinete Litterario. Na verdade, sua distinção de quem poderia integrar a sociedade perpassou os princípios masculinos ainda bastante interessados em excluir as mulheres da esfera pública e mantê-las, por longa temporada, fora do universo científico e intelectual. Esta exclusão relaciona-se às leis sociais bastante respeitadas no século XIX e que confinavam a mulher em um "universo asséptico, distante de qualquer referência corporal ou sexual" (Gabrielle HOUBRE, 1998, p. 12). Talvez ele acreditasse, assim como muitos homens do período, que a leitura poderia corromper a mulher, "mergulhando-a em devaneios lânguidos ou exaltações febris; privando-a de sua inocência" (p. 14), fazendo-a perder a alma e comprometendo sua educação. Há também as questões referentes à posse de capital financeiro. Proibidas de figurar na esfera pública, elas não podiam exercer atividades remuneradas; desta forma não tinham meios pecuniários para sustentar as mensalidades da associação. Questões estas relacionadas à separação das esferas pública e privada e que Carole Pateman (2013) lembrou ser estratégia de dominação, não muito bem sucedida, pois a teoria feminista crítica apontou diferentes paradoxos em torno destas construções estanques.

É pensando nas táticas femininas para resistir às crenças e práticas patriarcais que lembramos não estarem elas completamente excluídas da vida pública. No caso goiano, mesmo que não tenham sido mencionadas em documentos de fundação do Gabinete, aventamos que já exercitassem a leitura bem antes de 1871 e que, antecedendo a oficialização de sua sociedade, elas já lessem obras da biblioteca. Para isto nos apegamos a memórias, como as de Ondina Albernaz (1992). Segundo conta, sua avó Jacintha Luiza, já no século XIX, assinava jornais diversos e passava os dias lendo insistentemente. O fato é que os indícios de sua participação desapareceram entre outros temas e fontes, tidos por maior relevância, foram destruídos ou nem sequer foram produzidos. Talvez esteja aí a dificuldade em se fazer história de mulheres e mostrar os diferentes aspectos das relações entre os sexos.

O fato de Jacintha manter assinaturas de jornais, adquirir livros e lê-los ao longo da segunda metade do século XIX deixa ver a fragilidade de argumentos que potencializam o temário das distâncias e dificuldades de contato entre as regiões brasileiras como argumento para um possível "insulamento". Goiás não era uma ilha e os relacionamentos inter-regionais existiam, mesmo que fossem dificultosos.

As mediações com outras regiões ocorriam por intermédio do tráfego de religiosos, comerciantes, viajantes e presidentes de província, nomeados pelo império. O trabalho desses mediadores, operando "a exportação e importação de livros [e ideais] entre línguas geográfica e culturalmente diversas" (LEÃO; FARIAS, 2016, p. 633), foi decisivo para a formação de "espaços nacionais" e para o cultivo da literatura em Goiás. O Gabinete Litterário foi palco dessas mediações; seus registros estão repletos de informações relativas à compra de livros ou ao recebimento de volumes mediante doações feitas por sócios e pelas sócias (efetivos/as e honorários).

Entre 1871 e 1892, a associação adquiriu vários livros nas cidades de São Paulo e do Rio de Janeiro (a Corte). As negociações eram feitas por intermédio de livreiros e, também, pela circulação de diferentes personagens entre Goiás e o litoral. Sempre que houvesse recursos em caixa, os diretores convocavam uma sessão para que se definissem quais obras seriam adquiridas. Os relacionamentos entre a diretoria do Gabinete e o Dr. B. L. 
Garnier, proprietário da Livraria Garnier no Rio de Janeiro, confirmam o contato de Goiás com outras regiões brasileiras. Os registros comerciais entre estas instituições constam de 1873 até 1925.

Em 16 de agosto de 1871, após observar a existência de dinheiro em caixa, o presidente Antônio Felix de Bulhões Jardim declarou tomar ao seu cuidado a aquisição dos livros. De pronto "resolveu-se que se mandassem comprar na livraria Garraux, em S. Paulo, para serem conduzidos pelo Capitão Joaquim Martins Xavier Serradourada, as obras indicadas na encomenda" (GABINETE LITTERARIO GOYANO, 1871, p. 38). Na referida remessa constavam títulos de José de Alencar, Joaquim Manoel de Macedo, Alexandre Dumas, Chateaubriand, Georges Sand, Walter Scott, P. de Kock, entre outros volumes. Compras do tipo foram realizadas durante todo o período em que os Bulhões estiveram no controle político do Estado de 1871 até 1909.

As doações de livros eram muito frequentes, e entre elas constam as efetivadas pelo Presidente da Província Antero Cícero de Assis, do Presidente da Província do Ceará, Heráclito Graça, do Dr. Luiz Gonzaga Confúcio de Sá, "dos Senhores Desembargadores J. B. Carneiro, Luiz G. Fleury, Ant. ${ }^{\circ}$ d'Oliveira Andrade, Dr. Montelvade, Octavio A. Confúcio, Raphael Perillo e Conselh. ${ }^{\circ}$ A. A. Padua Fleury" (GABINETE LITTERARIO GOYANO, 1886-1887, p. 15-16). Um personagem frequente nas doações era o escritor Dr. Alfredo de Escragnole Taunay. Sócio honorário do Gabinete, Taunay doou "varias obras das quais algumas já se receberam pelo Dr. Luiz Rodrigues de Moraes Jardim" (GABINETE LITTERARIO GOYANO, 1873, p. 47).

As mulheres também desempenharam o papel de "beneméritas" do Gabinete Litterario. Elas doaram volumes bibliográficos que compuseram o acervo da biblioteca. Durante sessão de 17 de junho de 1872, após anunciar ter João Gonzaga de Siqueira doado o "jornal das Famílias dos meses de Janeiro, Fevereiro, Setembro, Outubro, Novembro, Dezembro de 1871 e de Fevereiro, Março, Abril e Maio de 1872" (GABINETE LITTERARIO GOYANO, 1872, p. 43), o secretário assinalou a doação de Silvina Ermelinda Xavier de Britto, que constava dos seguintes títulos:

[...] Marilia de Dirceu em 2 volumes - Vicentina em 3 v.es - O Forasteiro em 1 dito Mocidade de D. João $5^{\circ}$ em 4 ditos - Historia do descobrimento da América em 2 ditos - Um conto ao Serão em 1 dito - Estracto da Bíblia em 1 dito - Livro do povo em 1 dito - Honra e gloria ou 29 em 1 dito - e Almanach de lembranças brasileiras em 2 ditos [...]. (p. 43)

As obras foram recebidas com grande satisfação, "bem como as que forão offerecidas pelos Senhores Desembargadores Azeredo, Francisco de Faria Albernaz, Joaquim Gomes de Oliveira" (GABINETE LITTERARIO GOYANO, 1888, p. 19) e o "romance de Julia de Mello, oferecido pela Sen. a D. Rita F. Povoa" (p. 19).

Para além das doações também havia, no interior da associação, uma economia literária. Muitas pessoas comercializavam seus livros, coleções de jornais e de revistas. Em 13 de março de 1878 foram apresentadas duas propostas à mesa diretora do Gabinete, uma de João José de Azevedo "oferecendo a venda das seguintes obras: História universal de Parley, Geologie, La Plante, Selecta de autres classics, Dicionario inglez português e vice versa, Zoologie, Les enfants" (GABINETE LITTERARIO GOYANO, 1885, p. 11) e uma proposta de "D. Maria Luisa do Couto Brandão para venda das seguintes obras: Cecilia ou a filha do mysterio, Dicionario portuguez, de Roquette" (p. 11).

No ano de 1885, outra mulher fez proposta de venda de livros. Em 04 de maio, após Joaquim Fernandes de Carvalho oferecer "para venda sua coleção de 9 annos do Correio Official e outra de Tribuna Livre" (p. 11), foi a vez de "D. Jacintha do Couto Brandão [oferecer] também para venda diversas obras, sem especializar o preço de cada uma" (p. 11). 
As doações e/ou as vendas de livros efetivadas pelas goianas nos sugeriu algumas perguntas e oportunizou corroborar questões levantadas em torno da instrução das mulheres, de seu exercício da leitura, da mediação/circulação intelectual em Goiás e das táticas manejadas por elas a fim de exercitar sua intelectualidade, ainda que thes fosse apresentado um caminho cheio de obstruções.

\section{Goianas leitoras e a vontade de emancipação: o caso de Silvina e Jacintha}

Por conta de problemas financeiros, o Gabinete, fundado em 1864, precisou paralisar seus serviços em 1868. Segundo consta dos registros de ata, as causas de seu fechamento foram a exiguidade de recursos financeiros que ajudariam na manutenção dos serviços de empréstimo e compra de livros. Todavia, cabe anotar que os problemas financeiros poderiam ser provocados pela perda de sócios, aspecto muito relacionado aos conflitos políticos desenrolados durante as eleições dos novos diretores da associação, a cada eleição da mesa diretora.

"O Centro irradiador de cultura de Goiás daquela época foi o acervo do Gabinete Literário da velha capital" (MORAES, 1972, p. 119). A sociedade que o mantinha era composta de importantes representações políticas do estado e sua importância como canal de decisões administrativas pode ser notada na dinâmica das eleições, na saída e entrada de sócios e na oferta (ou retirada) de subvenções, por parte dos presidentes da província, para auxiliar em sua manutenção. O fato de ser um ambiente profícuo à atividade política transformou-o em local imprescindível aos interesses de grupos oligárquicos desejosos de projetar-se no cenário político estadual e nacional. Talvez seja por esta razão que Antônio Felix de Bulhões Jardim e Leopoldo de Bulhões Jardim tenham ocupado, em diferentes momentos, a presidência da associação.

No ano de 1868 ocorreram duas reuniões para deliberar sobre a situação financeira do Gabinete. Em 09 de fevereiro o presidente interino, Sr. Ignacio Antônio, destacou que a associação não tinha "receita nem para o indispensável pagamento do bibliotecário por se terem retirado quase todos os sócios" (GABINETE LITTERARIO GOYANO, 1868, p. 30) e que o melhor seria suspender o funcionamento de sua biblioteca. Em 01 de março resolveu-se que seriam suspensos os serviços do Gabinete até as deliberações da Assembleia Legislativa e que se depositassem os livros no "Lycêo, sob a confiança do respectivo Secretario, para cujo fim se deve pedir à Presidencia a necessaria faculdade, podendo delle gosar do beneficio da leitura aq.les socios que quiserem continuar a contribuir para esta associação" (p. 30). Após esta sessão não houve maiores registros. As reuniões dos associados só foram retomadas em 1871 .

Na sessão do dia 19 de fevereiro de 1871, reuniram-se no Lycêo de Goyaz vários sócios do Gabinete e, após deliberarem sobre a situação do acervo e da própria instituição, Antônio Felix de Bulhões, "jornalista, poeta, magistrado, político [e] 'verdadeiro articulista da oligarquia bulhônica'" (MORAES, 1972, p. 42), interferiu e declarou que tomaria para si a responsabilidade das providências que precisariam ser ajustadas para a reabertura da instituição. Como a esta época já era possível observar o protagonismo da oligarquia Bulhões no cenário político de Goiás, não nos pareceu estranho o acatamento, por todos os presentes, das decisões de Felix de Bulhões. A esta época (1870-1880) o "clã bulhônico, em toda a sua pujança, fez dele um mito, supervalorizando suas ideias, suas posições, sua ação e reação política" (MORAES, 1972, p. 42). Felix de Bulhões, embora tenha sido observado por Bretas (1991) como pouco preocupado com o fortalecimento do acervo do Gabinete Litterario, era bastante respeitado entre a população goiana e a classe política local e nacional. 
No dia 26 de março, os sócios convocaram nova sessão para retomar os trabalhos, avaliar a situação de seu acervo, eleger nova direção e registrar a entrada de novos sócios. Foi neste momento que se efetivou a entrada de mulheres em seu quadro de associados. Durante a reunião foram anunciados os nomes de treze senhoras que "desejavam fazer parte da sociedade":

D. Antonia Emilia de Bulhões Jardim; D. Maria d'Abbadia Vieira D'Aguiar; D. Silvina Ermillinda X.er de Britto; D. Anna Barbosa X.er Leal; D. Luisa da Silveira Pinto; D. Leonor Gertrudes Fialho dos Guim.s; D. Francisca Craveiro de Sá; D. Victoria Craveiro; D. Maria Cyriaca Ferreira; D. Anna Joaquina Marques Silva; D. Thomasia Pereira d'Abreu Brandão; D. Olympia Augusta Jardim de Bastos; D. Adelaide da Rocha Lima" (GABINETE LITTERARIO GOYANO, 1871, p. 34). (grifo nosso).

As treze associadas poderiam ler as obras da biblioteca, participar das sessões do Gabinete e até votar nas sessões, só não poderiam ocupar cargos na presidência da associação. Ainda neste ano, foi pedido pelo presidente Felix Bulhões, durante sessão de 16 de abril, que se adicionasse aos estatutos o seguinte artigo: "As senhoras que forem socias do Gabinete, e não puderem ou não quizerem concorrer pessoalmente ás sessões, podem fazer-se representar por terceira pessoa expressamente autorizada para isso" (GABINETE LITTERARIO GOYANO, 1871, p. 36).

Esta alteração dos estatutos foi posta em votação, convenientemente, na ocasião da propositura de novas associadas e associados. Neste dia, foram aceitas como sócias do Gabinete Litterario "Mathilde Alexand. Carlos, Adelaide P. de Mello, Maria Nazareth de Bulhões Jardim, Josefina Adelaide de Bulhões Jardim, Luiza Ferr. Coelho d'Oliveira, Maria Jenoveva Moraes, Luiza Jardim, Luzia Serrad. Póvoa, Joaq.na de Moraes Barros" (p. 36) e alguns homens influentes de Goiás.

A mudança nos estatutos, permitindo que as sócias fossem representadas por procuração, poderia ser um mecanismo útil à eleição de presidentes e diretores próximos da oligarquia dos Bulhões. Estratégia que os beneficiaria, uma vez que o Gabinete e as diferentes instituições públicas de Goiás podem ser encarados como palco para se debater a política partidária que antecipava o evento da República. Se o Gabinete, como diferentes instituições, poderia servir de espaço para debates e decisões políticas, não seria a permissão para as mulheres engrossar o quadro de sócios da associação, mediante a condição de manterem-se "mulheres honestas", uma estratégia das lideranças oligárquicas para se projetar no cenário político local?

O fato de os sobrenomes dos sócios e das sócias serem semelhantes, indiciando relações de parentesco, corrobora nossas suspeitas. Muitas eram mães, esposas, filhas, primas e/ou tias dos homens que dirigiam o Gabinete Litterario. Isto evidenciava que a sua filiação não se pautava apenas na necessidade de garantir espaços para que as mulheres se expressassem ou se emancipassem.

Pareceu-nos que a intenção era utilizá-las, como "cédulas em branco" nas eleições do Gabinete e em decisões que extrapolavam os limites da atividade intelectual, indo dar no campo da política partidária. Observando com cuidado, nota-se que Antônio Felix de Bulhões Jardim, era filho de Antônia Emília de Bulhões Jardim, irmão de Maria Nazareth de Bulhões Jardim e Josefina Adelaide de Bulhões Jardim e primo de Luiza Rodrigues Jardim, mulheres que haviam se associado ao Gabinete em 26 de março de 1871.

Destacamos que, embora Antônia Emília tenha sido identificada por Moraes (1972, p. 41) como uma mulher "altamente feminista", não houve, por parte dela, de suas filhas e de suas parentas um movimento em defesa da emancipação feminina. As mulheres da família Bulhões e de outras famílias abastadas e instruídas de Goiás não se moveram na 
defesa de direitos políticos ou do sufrágio universal. Tal ação se limitou às cinco goianas que integravam diferentes agrupamentos familiares, sem grande projeção na cena política de Goiás à época dos pedidos de voto.

O estímulo para se aceitar mulheres como sócias da associação poderia ser as dificuldades financeiras dos anos 1864 até 1868. Seu caráter de votantes nas eleições do Gabinete e suas relações de parentesco com homens influentes e economicamente abastados de Goiás também justificariam sua entrada na Associação. Deve ter sido por esta razão que só se aceitavam "mulheres honestas" e que tinham condições financeiras para manter as mensalidades correspondentes ao empréstimo de livros. Deve ser também por esta razão que as novas sócias tinham sobrenomes muito parecidos aos dos sócios. Elas eram "mães" e "filhas" de famílias burguesas de Goiás e que gozavam de grande respeito naquele meio.

As relações entre os sexos, no interior do Gabinete, eram atravessadas pelo poder e pela dominação masculina, explicitadas em parcos registros de ata e que recorrem à honestidade, honra e aos comportamentos que se esperava de mulheres desejosas em associar-se à agremiação literária. Durante sessão convocada com o objetivo de reformar os estatutos do Gabinete, em 28 de março de 1873, foi destacado que se autorizava a entrada de mulheres, sob a regra de que fossem "senhoras honestas" (GABINETE LITTERARIO GOYANO, 1873, p. 49).

A referência à "honestidade das sócias" é um elemento característico do valor que se dava à defesa da honra naquele momento. O comportamento adequado de mulheres como regra para engordar as fileiras da associação se relacionam ao manuseio de "categorias e normas sexuais num contexto mais abrangente de relações de poder" (Sueann CAULFIELD, 2000, p. 35). É um projeto de disciplinamento dos corpos, dos comportamentos e da sexualidade de mulheres e homens. Caulfield lembra que "as ofensas à honra sexual das mulheres eram mais complexas", isto porque "elas podiam ofender [...] a integridade individual ou o patrimônio familiar" (p. 59). Questão que também foi observada por Carlos Alberto Dória (1994) no instante em que discutiu a honra como tema da cultura e na sociedade ibero-americana. No caso do Gabinete, uma mulher desonesta e, consequentemente, desonrada colocava em cheque a autoridade moral da instituição, que era por sua vez gerida por homens honrados. A desconfiança de que, embora honradas, as mulheres estavam cotidianamente ameaçadas pela desonra expressa uma das razões de elas não terem assumido cargos de direção. As mulheres eram continuamente enxergadas como agentes em situação de perigo.

Todavia, o fato de não terem assumido cargos de direção e sequer terem a garantia de que votariam nas eleições do Gabinete, não as impediu de sonhar e projetar esteticamente um ensaio emancipacionista. Embora as estratégias de dominação simbólica as tenham calado no interior das decisões tomadas na agremiação literária, vale destacar que algumas souberam manejar a dominação masculina a seu favor.

Elas se calaram em determinados momentos para exercer algum poder mais adiante. Foi exatamente isto o que fizeram Silvina e Jacintha ao longo de sua permanência na referida instituição. Suas táticas, manejadas no Gabinete ou em escolas, refletiram-se na solicitação para votar nas eleições estaduais de 1889. Frisamos que, mesmo manejando táticas, não temos informações suficientes para destacar a instrução como uma garantia da emancipação política e civil. A instrução poderia ser um canal ou uma via para alcançar a emancipação.

Na segunda metade de 1889, Jacintha Luiza do Couto Brandão Peixoto, Silvina Ermelinda Xavier de Brito, Maria Santa Cruz de Abreu, Barbara Augusta de Sant'Anna e Virginia Vieira, goianas, efetivaram um pedido ao juiz substituto Sebastião Fleury Curado 
para votar nas eleições estaduais daquele ano. Por razões não identificadas ainda, a imprensa local não deu grande visibilidade à solicitação. O jornal Goyaz apenas publicou uma nota intitulada "Eleitoras" e que trazia, além dos nomes das solicitantes, o seguinte comentário: "Consta-nos que outras vão fazel-o. O dr. Sebastião Fleury que não faça do sexo condição de idoneidade para o direito de voto" (GOYAZ, 1989, p. 03).

Embora o documento mencione que outras mulheres solicitariam tal direito, não encontramos maiores pistas de goianas interessadas em emancipar-se politicamente, naquele ano. O que percebemos é que as goianas, ao solicitar que se ampliasse o sufrágio para elas, se assemelharam ao que faziam muitas brasileiras e estrangeiras, conforme apontou Branca Moreira Alves (1980), June Hahner (2003) e Maria Fernanda Baptista Bicalho (1988). Observando a legislação correspondente ao direito de voto, percebemos que as mulheres goianas e brasileiras teriam alicerçado suas solicitações nas brechas presentes no texto da lei. De acordo com o artigo segundo da lei n. 3020 de 09 de janeiro de 1881 e no art. $2^{\circ}$ do decreto número 8213 , de 13 de agosto do mesmo ano, eleitor era todo "cidadão brazileiro, nos termos dos arts. $6^{\circ}, 91$ e 92 da Constituição do Imperio, que tivessem renda liquida annual não inferior a $200 \$$ por bens de raiz, industria, commercio ou emprego" (MINISTÉRIO, 1881, p. 533).

Com esta interpretação, as mulheres de diferentes lugares do Brasil e as goianas devem ter compreendido que a categoria "cidadão" se referia ao gênero masculino e feminino. Interpretação que foi contrariada, em Goiás, pela negativa de Sebastião Fleury. Suspeitamos que os pedidos das mulheres, baseados nas brechas do texto legal, logo se tornaram um problema. Sobre tal questão cabe a observação de Scott sobre a experiência francesa: ao "descobrir como as feministas poderiam dar à mulher o status de indivíduo autônomo, auto representável e com plenos direitos políticos numa república democrática" (SCOTT, 2002, p. 25), os homens manejaram discursos para negar-Ihes sua cidadania. No caso brasileiro, as negativas ao direito de voto persistiram após a proclamação da República. As "mulheres foram esquecidas e silenciadas na Constituição de 1891, art. 70, que estabeleceu o sexismo político, ao sancionar que apenas cidadãos, maiores de 21 anos e alfabetizados seriam considerados eleitores". (Noêmia LUZ; Alcileide NASCIMENTO, 2014, p. 355).

A negativa para o caso das goianas evidenciou as contradições do direito e as estratégias masculinas, que manejavam discursos filosóficos, a fim de mantê-las afastadas das instâncias de poder. A alegação da inexistência de um individualismo para as mulheres estaria fortemente relacionada ao que Scott chamou de construção social da subalternidade feminina.

Embora as mulheres não estivessem mencionadas na legislação - o que parece ser uma omissão intencional - e tivessem utilizado de tal omissão para exigir uma igualdade de direitos com os homens, quando tal pressão era executada por elas - e embora houvesse alguns homens que reconhecessem a deficiência do direito em não mencioná-las - as negativas jurídicas se apoiavam na inexistência de leis específicas ao seu sexo e o fato de estarem tuteladas por seus esposos, pais, irmãos e filhos.

Sebastião Fleury negou, pelo menos a Jacintha, o direito de votar, por conta de seu esposo ainda estar vivo na ocasião da solicitação. Temos fortes razões para crer que, muito apegado à predisposição masculina do campo político e num individualismo fortemente pautado no masculino, ele ocultou o fato de as goianas, pelo menos Jacintha e Silvina, desempenharem atividades remuneradas.

Jacintha Luiza do Couto trabalhava na produção de doces, quitandas e de fumo. Embora sua neta, Ondina de Bastos Albernaz (1992), tenha dado maior visibilidade à sua intensa atividade leitora, é Jacintha quem aparece, em 24 de outubro de 1890, tomando 
10 "acções da Companhia Industrial Goyana" (GOYAZ, 1890, p. 04). Sua participação entre os sócios do Gabinete também é evidência de que exercesse alguma atividade remunerada, do contrário como pagaria as mensalidades de empréstimos das dezenas de livros que lia? Ou mesmo manteria as assinaturas de jornais e revistas registradas nas memórias de Ondina Albernaz?

Nos registros de ata não encontramos seu nome entre as novas associadas, a exemplo do que ocorreu no caso de Silvina Ermelinda; entretanto foi bastante comum encontrar recados mandados por ela pedindo que Ihe enviassem os livros de seu desejo. Sua presença na instituição deve ter sido efetivada com ares de certa informalidade, o que não é de se estranhar, uma vez que muitas mulheres também mantinham relações informais com o Gabinete, ou mesmo que sua entrada não tivesse sido registrada por razões que desconhecemos.

Jacintha e Silvina participavam ativamente do Gabinete Literário, mais até que Maria Santa Cruz, Bárbara Augusta e Virginia Vieira. Silvina, conforme apresentado anteriormente, já integrava o quadro de sócios desde 1871 e seu nome sempre aparecia nas "Relações dos sócios do Gabinete Litterario Goyano que contribuirão com suas mensalidades". Jacintha também apareceu entre os registros do Gabinete Literário desde 1871.

Ainda que seu nome não esteja relacionado entre as associadas de 1871, talvez por não ter condições de manter as mensalidades, uma vez que sua família encontrava-se em difícil situação econômica ou porque não estivesse em Goiás, mas na Fazenda Paraíso, um bilhete colado no registro de ata deste ano dá notícia de suas solicitações:

Senr. Tonico

Remetto-lhe o ultimo volume dos Escolhidos e Reprovados. Peço-lhe o favor de mandarme caso ahi esteja - Os Amôres de Aurora, no caso de não o encontrar esse peço-lhe mandar-me o Rei dos Bohemios ou Memorias de um Caixeiro.

Sua parenta

J. Luiza. (GABINETE LITTERARIO GOYANO, 1871-1878, p. 37).

O bilhete de Jacintha é evidência importante de sua atividade intelectual, expressa na leitura de livros. Atividade que lhe investiu com uma aura de grande respeito no meio social goiano. O bilhete testifica sua atividade leitora e corrobora os registros de Ondina de Bastos Albernaz, no momento em que anotou as memórias que tinha da avó:

Temperamental e de uma franqueza que chegava às raias da rudeza, porém era inteligente e de cultura avançada para a época. Lia espanhol e italiano, e falava francês fluentemente. Mantinha intercâmbio cultural e comercial com grandes magazines francesas; recebia da França jornais e revistas, comprava perfumarias, tais como óleo para cabelos, sabões, cosméticos, remédios e obras de arte. Desligada das lides domésticas dedicava-se inteiramente à literatura, tendo repassado o acervo da Biblioteca Pública.

Em seu banco, um assento baixo, de um a dois palmos de altura, passava os dias em intermináveis leituras, com jornais esparramados pelo chão, era seu modo de ler. Assinante constante de jornais, como O Paiz, O Jornal e o Correio da Manhã. [...] (ALBERNAZ, 1992, p. 47, grifos nossos).

É importe ressaltar que, embora seu nome não conste nas atas de sessões como uma sócia, quando manipulamos os livros contendo registros de leitura conseguimos confirmar sua intensa atividade leitora. Entre 1900 e 1901 Jacintha leu cinquenta e três obras do Gabinete Literário. As dezenas de leituras variavam do romance aos registros de viagem. Entre tantos livros ela leu "Memórias do Diabo, O Grande Chefe dos Hincas, Ipsiboé, Voyages 
a província de Goyaz S. Hilaire, Maison Fellirr, Bel Ami e Collar do Diabo" (GABINETE LITTERARIO GOYANO, 1901, p. 168).

O fato de ser uma mulher viúva, combinado aos sérios problemas financeiros enfrentados pela família em fins do século XIX, deve ter exigido dela o desempenho de atividades remuneradas que não foram registradas no tempo. Talvez tenha sido por esta razão que ela tentou comercializar seus livros no Gabinete Litterario, em 1885. O exercício de atividades remuneradas deve ter sido o que the permitiu adquirir obras e assinar jornais e revistas nacionais e internacionais.

Clóvis Carvalho Britto (2009) e Rita Elisa Seda (2009), em livro sobre a poetisa Cora Coralina, filha de Jacintha, lembram com maestria partes de sua trajetória. Jacintha era uma mulher que gozava de grande respeito em Goiás, tanto que na ocasião de seu aniversário o jornal Voz do Povo (1934, p. 02) publicou uma nota destacando-a. Em 04 de novembro de 1934, o jornal trouxe felicitação em homenagem ao seu natalício.

Sabemos que era comum a publicação de notas de felicitações para pessoas influentes da cidade e estado de Goiás, mas elas vinham agrupadas numa única coluna do jornal e sempre na última página. No caso de Jacintha havia uma distinção e um destaque. A felicitação veio no centro do jornal, entre notícias de cunho políitico e na página de número dois. Vale lembrar que este jornal era representativo das ideias mudancistas, defendiam a necessidade de transferência da capital goiana, desta forma era uma oposição a Jacintha, pois conforme lembraram Britto e Seda (2009) e Maria Bittar (2002) ela se posicionou contrária à transferência da capital.

Silvina Ermelinda Xavier de Britto trabalhava como professora da escola feminina instalada em Goiás na Rua Direita, n. ${ }^{\circ} 13$ (atual Moretti Foggia) desde 1867 (Célia SEIXO DE BRITTO, 1982, p. 125). Em 1871, o Correio Official destacou matéria sobre o exercício de docência de Silvina e seu pedido de transferência da escola para outro prédio na Rua do Mercado (CORREIO OFFICIAL, 1871, p. 03). Silvina também era uma sócia assídua do Gabinete Literário Goyano. Esta informação evidencia sua atividade intelectual e remunerada, pois para manter suas leituras ela precisaria pagar as mensalidades.

O fato de exercer atividades remuneradas e ocupar a cadeira de professora de instrução pública em Goiás deve ter sido um incentivo para que adquirisse livros, tornandose uma ávida leitora. Foram encontrados vários registros de pagamentos efetuados entre os meses de janeiro a dezembro de 1878 ao tesoureiro do Gabinete Literário Goyano. Entre esses meses Silvina pagou ao Gabinete Literário a quantia de 17\$000 (dezessete mil réis) em mensalidades. (GABINETE LITTERARIO GOYANO. 1878, p. 32).

Maria Santa Cruz de Abreu, Bárbara Augusta de Sant'Anna e Virginia Vieira praticamente desapareceram dos registros de jornais e memórias. Sobre Bárbara apenas sabemos que era mãe de Alice Augusta de Sant'Anna Coutinho, uma das jovens que compartilhou espaço junto de Leodegária de Jesus, Cora Coralina e Rosa Godinho em atividades escriturárias nos jornais de Goiás em meados do século XX.

Retomando as questões relacionadas aos pedidos de voto, enfatizamos que Sebastião Fleury não explicou a razão da negativa para as outras mulheres. E em 1889 não foram encontradas publicações que permitissem esclarecer as razões de sua negativa, pelo menos não em Goiás. A imprensa goiana não tornou visível a solicitação das goianas. Foi o jornal A Familia quem deu maior importância ao pedido feito por Jacintha, Silvina, Maria, Barbara e Virginia, conforme se pode notar na matéria:

A comprehensão dos destinos das pessoas do nosso sexo, está tomando no Brazil, uma attitude digna dos maiores applausos. Já se pensa em influir nos destinos sociaes, em sahir da nullidade completa em que temos vivido até agora. Em Goyaz, requereram 
inclusão no alistamento eleitoral as Sras. D. D. Jacintha Luiza do Couto Brandão Peixoto, Silvina Ermelinda Xavier de Brito, Maria Santa Cruz de Abreu, Barbara Augusta de Sant'Anna e Virginia Vieira. Em principio, nada se conseguirá; mas com resolução e constância chegaremos a obter fudo o que a sociedade nos deve e a lei não consente. (A FAMILIA, 1889, p. 03).

O texto do jornal feminino é bem mais detalhado do que aquele publicado no Goyaz e aqui a iniciativa das goianas é característica de grande expressão no rol da luta de mulheres pelo reconhecimento de sua cidadania e ampliação do sufrágio universal. Entretanto, não oferece grandes pistas para esclarecermos as razões que moveram estas mulheres em tal solicitação.

Não conseguimos identificar se o interesse pelo voto seria algo relacionado à vontade de exercer atividades políticas ou se era algo diretamente relacionado com uma nascente consciência de gênero. Um aspecto que o documento ajudou a esclarecer é o de que, naquele momento, ainda não lhes era autorizado exercer atividades eletivas e/ou políticas. Porém a redatora reconhecia que mesmo não conquistando o direito de votar, "com resolução e constância [as mulheres chegariam] a obter tudo o que a sociedade [lhes] devia e a lei não [Ihes consentia]" (A FAMILIA, 1889, p. 03).

Após esta publicação, não encontramos maiores referências à movimentação das goianas em defesa da emancipação feminina no século XIX. Maiores explicações para este caso só foram dadas pelo próprio Sebastião Fleury, cinquenta anos depois.

Percebendo que o ato de suas conterrâneas tratava-se de algo transgressor, o juiz publicou, por meio de memórias, as razões de negar o pedido de voto, pelo menos para Jacintha Luiza: D. Jacintha foi talvez a primeira brasileira precursora do movimento feminista que apesar
de casada com o Dr. Lins Peixoto requereu seu alistamento no quadro das eleitoras
brasileiras e coube-me, aos 24 anos de idade, como Juiz de Direito, decidir o caso [...].
E quase meio século depois lendo-se a decisão que eu proferi percebe-se que um dos
mais importantes argumentos está na circunstancia de se achar sujeita D. Jacintha ao
poder marital, pois que ainda vivia o Desor. Peixoto, seu marido. Ora, a suplicante era
casada sob o regime de comunhão de bens, como confessa, está sujeita, portanto, ao
poder marital, não tendo a livre administração de seus bens, não pode alienar, não
pode aparecer em juízo sem assistência ou autorização do marido, que é seu
representante civil. Falece-lhe, pois, uma das condições da capacidade eleitoral.
Sebastião Fleury Curado (CURADO, 1936, p. 01).

As justificativas utilizadas por Sebastião Fleury vão de encontro às questões que denunciam o peso da dominação simbólica e o poder de que usufruía a representação masculina na cena pública. Todavia, Sebastião Fleury soube reconhecer que a ação de Jacintha tratava-se de algo transgressor e importante. Tanto que guardou o processo contendo o pedido para votar e o lembrou em 1936.

Ao longo dessas linhas, avaliamos alguns exemplos de empreendimentos femininos esperançosos por algum protagonismo. A entrada das mulheres no Gabinete Literário Goyano, logo após sua reabertura, em 1871, as doações/vendas de livros e os pedidos de voto feitos pelas goianas são demonstrações de que as mulheres nem sempre aceitaram em silêncio a condição subalterna que tentavam lhes impor.

Estas mulheres, especificamente Silvina e Jacintha, vislumbraram, no interior do exercício de poder dispensado pelos homens, muitas rachaduras. E foram por estas rachaduras que elas tentaram fazer infiltrar suas demandas, expectativas, experiências e desejos. Embora não tenham alcançado o êxito projetado, o que se percebe é a compreensão, por parte delas, da maquinaria de jogos no interior das relações entre os sexos. As mulheres entenderam

14 Revista Estudos Feministas, Florianópolis, 26(2): e 
que "o poder não tem sua sede apenas no centro, no Estado, [mas que] existe todo um sistema de micro poderes, de relações e de revezamento" (PERROT, 2005, p. 263) que podem ser alteradas no ritmo dos relacionamentos entre os sexos.

\section{Referências}

A FAMILIA. Novidades. "Eleitoras". Côrte, anno I, n 39, 23 nov. 1889, p. 03

ALBERNAZ, Ondina de Bastos. Reminiscências. Goiânia: Kelps, 1992.

ALVES, Branca Moreira. Ideologia e feminismo: a luta da mulher pelo voto no Brasil. Petrópolis: Vozes, 1980.

BARRA, Valdeniza Maria Lopes da. "Livros e leituras do Gabinete Literário Goiano na sociedade oitocentista de Goiás". Educativa: Revista do Programa de Pós-graduação em Educação - PPGE. Pontifícia Universidade Católica de Goiás (PUC-GO), Goiânia, v. 11 , n. 01, p. 85-97, jan./jun. 2008.

BICALHO, Maria Fernanda Baptista. O Bello Sexo: imprensa e identidade feminina no Rio de Janeiro em fins do século XIX e início do século XX. 269 p. 1988. Dissertação (Mestrado em Antropologia Social) - Programa de Pós-Graduação em Antropologia Social do Museu Nacional, Universidade Federal do Rio de Janeiro, Rio de Janeiro, RJ, Brasil.

BITTAR, Maria José Goulart. As três faces de Eva na Cidade de Goiás. Goiânia: Kelps, 2002. BRETAS, Genesco Ferreira. História da Instrução Pública em Goiás. Goiânia: CEGRAF/UFG, 1991.

BRITTO, Clóvis Carvalho; SEDA, Rita Elisa. Cora Coralina: raízes de Aninha. Aparecida: Idéias \& Letras, 2009.

CANEZIN, Maria Teresa; LOUREIRO, Walderês Nunes. A escola normal em Goiás. Goiânia: UFG, 1994.

CAMPOS, Francisco Itami. Coronelismo em Goiás. Goiânia: UFG, 1987.

CAPDEVILA, Luc. "Résistance civile et jeux de genre France-Allemagne-Bolivie-Argentine, Deuxième Guerre Mondiale - années 1970-1980". Annales de Bretagne et des Pays de l'Ouest. França: Presses Universitaires de Rennes, Rennes, tomo 108, n. 2, 2001

CAULFIELD, Sueann. Em defesa da honra: moralidade, modernidade e nação no Rio de Janeiro (1918-1940). Campinas: Unicamp, 2000.

CHARTIER, Roger. "Diferenças entre os sexos e dominação simbólica (nota crítica)." Cadernos Pagu. Campinas, n. 04, p. 37-47, 1995.

CORREIO OFFICIAL. Noticias. Goyaz, 11 nov. 1871, p. 03.

Noticias locaes. Goyaz, 19 dez. 1874, p. 03.

Concerto musical. Goyaz, 17 nov. 1880, p. 04.

CURADO, Sebastião Fleury. "Feminismo". Folha de Goyaz, Goiás, 26 abr. 1936, p. 01.

DIAS, Maria Odila Leite da Silva. Quotidiano e poder em São Paulo no século XIX. São Paulo: Brasiliense, 1984.

DÓRIA, Carlos Alberto. "A tradição honrada (a honra como tema de cultura e na sociedade íberoamericana)." Cadernos Pagu, Campinas, SP, v. 2, p. 47 - 11 1, jan /jun., 1994.

GABINETE LITTERARIO GOYANO. "Acta da sessão do dia 09 de fevereiro de 1868". In: Livro 10 das actas das sessões. Goiás: Gabinete Litterario Goyano, 1868, p. 03.

"Acta da sessão do dia 26 de Março de 1871". In: Livro $1^{\circ}$ das actas das sessões. Goiás: Gabinete Litterario Goyano, 1871, p. 34-36.

"Acta da sessão do dia 16 de agosto de 1871 ". In: Livro $1^{\circ}$ das actas das sessões. Goiás: Gabinete Litterario Goyano, 1871, p. 38-40.

. "Acta da sessão do dia 17 de junho de 1872". In: Livro 10 das actas das sessões. Goiás: Gabinete Litterario Goyano, 1872, p. 43-44. 
"Acta da sessão do dia 26 de fevereiro de 1873". In: Livro $1^{\circ}$ das actas das sessões. Goiás: Gabinete Litterario Goyano, 1873, p. 47.

"Acta da sessão do dia 28 de Março de 1873". In: Livro $1{ }^{\circ}$ das actas das sessões.

Goiás: Gabinete Litterario Goyano, 1873, p. 49.

"Bilhete avulso de Jacintha Luiza". In: Livro de registro de leituras de 1871 a 1878.

Goiás: Gabinete Litterario Goyano, 1871-1878, p. 37.

Livro de registro de mensalidades recebidas pelo bibliotecário e procurador do

Gabinete. Goiás: Gabinete Litterario Goyano, 1878, p. 32.

. "Acta da sessão do dia 04 de maio de 1885". In: Livro $2^{\circ}$ das actas das sessões.

Goiás: Gabinete Litterario Goyano, 1885, p. 11.

. "Acta retrospectiva dos factos mais salientes ocorridos de 20 de junho de 1886 a

1887 no Gabinete Litterario Goyano". In: Livro $2^{\circ}$ das actas das sessões. Goiás: Gabinete LitteraLrio Goyano, 1886-1887, p. 15-16.

"Acta da sessão do dia 05 de janeiro de 1888". In: Livro $2^{\circ}$ das actas das sessões.

Goiás: Gabinete Litterario Goyano, 1888, p. 19.

. Livro de registro de Sócios, n. 18, ano 1901. Goiás: Gabinete Litterario Goyano, 1901 , p. 168.

GINZBURG, Carlo. Nenhuma ilha é uma ilha: quatro visões da literatura inglesa. São Paulo: Companhia das Letras, 2004.

GODOY, Maria Paula Fleury de. Do Rio de Janeiro a Goiás - 1896 (A viagem era assim). Belo Horizonte: Oficinas Gráficas de Velloso S.A., 1961.

GOYAZ. Eleitoras. Goyaz, 27 set. 1889, p. 03 Acções. Goyaz, 24 out. 1890, p. 04.

HAHNER, June E. Emancipação do sexo feminino: a luta pelos direitos da mulher no Brasil (1850-1940). Florianópolis: Mulheres; Santa Cruz do Sul: EDUNISC, 2003.

HOUBRE, Gabrielle. "Como a literatura chega às jovens. França, primeira metade do século XIX." Revista Tempo. Niterói, n. 09, p. 11-27, jul. 1998.

MARQUES, Anna Joaquina da Silva. Memorial de Anna Joaquina da Silva Marques. Cidade de Goiás. 1880-1930. Manuscrito pertencente à 'Coleção da Cúria da Arquidiocese da Goiânia', sob a guarda do IPEHBC. Goiânia - GO.

LEÃO, Andréa Borges; FARIAS, Edson. "O popular no Brasil numa fábula de costume francesa: estéticas e mediações transatlânticas." Revista Sociedade e Estado. Brasília, v. 31 , n. 03 , p. 631-649, jul.2016.

LUZ, Noemia M. Q. P. da Luz, NASCIMENTO, Alcileide C. do. "O debate em torno da emancipação feminina no Recife (1870-1920)". Cadernos Pagu. Campinas, v. 42, p. 341-370, jan./jun., 2014.

MATTOS, Raymundo José da Cunha. Chorographia Histórica da Província de Goyaz. Goiânia: Líder, 1978.

MENDONÇA, Honorata Minelvina Carneiro de (1875). A Redenção. Goiânia: Kelps, 2010. "Saudades de minha terra. Parodia por uma goiana a sua irmã na Côrte". Jornal das Familias, Côrte, dez. 1868, p. 39-40.

MICHAUD, Stéphane. "Idolatrias: representações artísticas e literárias". In: DUBY, Georges; Georges; PERROT, Michelle. História das mulheres no Ocidente. v. IV. O Século XX. Porto: Edições Afrontamentos, 1991. p. 145-170.

MINISTÉRIO do Império. "Regulamento para a execução da lei eleitoral. Decreto n` 3.029 , de 09 de janeiro de 1881 ". In: Gazeta Jurídica. Revista mensal de Doutrina Jurisprudência e legis/ação. Rio de Janeiro: Typographia Perseverança, 1881, p. 533.

MORAES, Maria Augusta de Sant'Anna. Contribuição para o estudo político e oligárquico da história de Goiás. 1972. Tese (Doutorado em História) - Instituto de Ciências Humanas 
e Letras. Departamento de História e Geografia, Universidade de São Paulo, São Paulo, Brasil.

ORLANDI, Eni Puccinelli. As formas do silêncio: no movimento dos sentidos. Campinas: Unicamp, 2007.

PALACIN, Luiz. Goiás 1722-1822: estrutura conjuntura numa capitania de minas. Goiânia: Oriente, 1976.

PATEMAN, Carole. "Críticas feministas à dicotomia público/privado". In: MIGUEL, Luis Felipe e BIROLI, Flávia (Orgs.). Teoria Política feminista: textos centrais. Vinhedo: Editora Horizonte, 2013. P.55-79.

PERROT, Michelle. As mulheres ou os silêncios da história. Bauru: Edusc, 2005.

SAINT-HILAIRE, Auguste de. Viagem à província de Goiás. Belo Horizonte: Itatiaia, 1975.

SCOT, Joan Wallach. Género e historia. México: FCE, Universidad Autónoma de la Ciudad de México, 2008. 2002.

A cidadã paradoxal: as feministas e os direitos do homem. Florianópolis: Mulheres,

SEIXO DE BRITTO, Célia Coutinho. A mulher, a história e Goiás. 2. ed. Goiânia, 1982.

SOIHET, Rachel. Condição feminina e formas de violência: mulheres pobres e ordem urbana (1890-1920). Rio de Janeiro: Forense Universitária, 1989.

SPINOLA, Aristides de Sousa. Relatório apresentado pelo Exm. ${ }^{\circ} \mathrm{Sr}$. Dr. Aristides de Sousa Spinola a Assembléa Legislativa Provincial de Goyaz no dia $1^{\circ}$ de junho de 1879. (Continuação). In: Correio Official, Goyaz, 18 jun. 1879, Instrução Pública, p. 01.

VASCONCELOS, Eliane. "Precursoras da literatura goiana". Revista UFG, Goiânia, n. 8, p. 87 100, ano XII, 2010.

VOZ DO POVO. Jacintha Brandão. Goyaz, 04 nov. 1934, p. 02.

[Recebido em 28/03/2017, reapresentado em $27 / 11 / 2017$

e aprovado em 20/02/2018]

Poetics of the Emancipation of Women in the Goiano Backlands (19th Century) Abstract: The present text aims to understand how the spaces of instruction and reading existing in the old Goian capital (Goiás), in the second half of the 19th century and the beginning of the 20 th century, were (re) appropriated by some women in order to guarantee to them the expression of their experiences. In order to do so, starting from the documentation of the Goyano Literary Cabinet, created in 1864, we sought, through the protagonism of Silvina Ermelinda Xavier de Britto and Jacintha Luiza do Couto Brandão Peixoto, to understand the issues about the education of women, their exercise of reading, an essay on emancipation, represented by the calls for vote from Goiás' women in 1889 and the tactics handleb by these women in the expectation of exercising their intellectuality, although presented to them as a path full of obstructions.

Keywords: Women's emancipation; Intellectuals; Goyano Literary Cabinet; Education.

Paulo Brito do Prado (paulobritogo@yahoo.com.br) é doutorando em História Social pela Universidade Federal Fluminense (UFF-RJ), mestre em História Cultural pela Universidade Federal de Goiás (UFG-GO), especialista em Educação para a Diversidade e Cidadania pela Universidade Federal de Goiás (UFG-GO/CIAR), graduado em História pela Universidade Estadual de Goiás (UEG-GO) e é professor da rede estadual de ensino de Goiás.

Eliane Martins de Freitas (emartinsdefreitas@yahoo.com.br) é professora Associada I da Universidade Federal de Goiás, Regional Catalão (UFG-GO) no curso de 
História. É professora do Programa de Pós-Graduação em História - Mestrado Profissional em História/UFG/Regional Catalão. É doutora em História pela Universidade Estadual Paulista Faculdade de História, Direito e Serviço Social (UNESP-Franca-SP), mestre em História pela Universidade Estadual de Campinas (UNICAMP-SP) e graduada em História pela Universidade Federal de Uberlândia (UFU-MG). 